\title{
Testicular vein ligation and fertility in men with varicoceles
}

\author{
H W G BAKER, H G BURGER, D M DE KRETSER, B HUDSON, G C RENNIE, \\ W G E STRAFFON
}

\begin{abstract}
Pregnancy rates in 651 subfertile couples in which the man had a varicocele were analysed by life table methods and were not found to be significantly different before and after testicular vein ligation performed in 283 patients. Estimated proportions of couples conceiving were roughly $30 \%$ by one year and $45 \%$ by two years in both groups. The operation was also not associated with improvement in results of semen analysis. These findings suggest that testicular vein ligation for varicoceles does not improve fertility.
\end{abstract}

\section{Introduction}

Treatment of varicoceles by testicular vein ligation or other techniques has become an accepted management for male infertility in many centres, and despite reports claiming a beneficial effect of the operation on fertility and the concentration, motility, and morphology of sperm there have been no large scale controlled trials to confirm such claims. . $^{1.3}$ The relation between varicocele and infertility and the value of treatment has also been questioned. ${ }^{48} \mathrm{We}$ present an analysis of fertility and results from semen tests of 651 subfertile men with varicoceles.

\section{Patients and methods}

Infertile men were usually referred to us because their clinical features or results from semen analyses were abnormal. Between 1970 and June 1984 857 men with left sided varicoceles were seen. The sizes of the varicoceles were classified clinically as small, palpable Valsalva's impulse in the pampiniform plexus without dilatation; medium, palpable dilatation of the pampiniform plexus; and large, visible distension of the scrotal veins when standing.

Female partners were investigated in detail, including hysterosalpingography or laparoscopy to assess tubal patency and measurements of progesterone concentrations in the luteal phase to confirm ovulation. Out of 857 female partners 27 had bilateral tubal obstruction, 78 had unilateral tubal obstruction, 548 had bilateral tubal patency, and 204 were not investigated for tubal patency or investigations yielded conflicting results. In addition, 119 had miscellaneous uterine disorders, non-obstructing pelvic adhesions, or endometriosis. Twenty five women had persistent failure of ovulation, 134 ovulation induced by drug treatment, and 556 regular ovulation. Tests to confirm ovulation had not been performed or yielded conflicting results in 142 women.

Reproductive Medicine Clinic and Medical Research Centre, Prince Henry's Hospital, Melbourne, Australia, 3004

H W G BAKER, MD, FRACP, senior research fellow (also at Howard Florey Institute of Experimental Physiology and Medicine)

H G BURGER, MD, FRACP, professor of medicine

W G E STRAFFON, FRACS, FRCS, urologist

Howard Florey Institute of Experimental Physiology and Medicine, Melbourne, Australia

B HUDSON, MD, FRACP, medical director

Department of Anatomy, Monash University, Melbourne, Australia

D M DE KRETSER, MD, FRACP, professor of anatomy (also at Reproductive Medicine Clinic and Medical Research Centre)

O R Systems Pty Ltd, Melbourne, Australia

G C RENNIE, BSC, MA, statistician

Correspondence to: Dr Baker.
We excluded 127 couples from this analysis who were regarded as having no chance of achieving a pregnancy - that is, those with bilateral tubal obstruction, persistent anovulation, azoospermia, or no sperm motility or those who had normal sexual intercourse less than once a month. Also excluded were 22 couples in whom the wife was found to be pregnant at the time of the first visit and 57 who were seen only once and could not be contacted again. Thus the study group comprised 651 men with left sided varicoceles in partnerships in which no absolute barrier to fertility was detected. Varicoceles were also present on the right hand side in 267 of these men but were medium or large in only 46

Testicular vein ligations were performed in 283 men, usually by the same surgeon (WGES), by the technique of Palomo in $236,{ }^{9}$ an inguinal approach in 13 , and a scrotal approach in 34 . Operations were performed bilaterally in 164 and on the left side only in 119. Testicular vein ligations were not performed in 368 men before their partners conceived. Some patients received other treatments-for example, antibiotics for possible low grade inflammation of the genital tract, clomiphene or androgens for possible minor hormone deficiencies, or artificial insemination with the husband's semen-before or after the operation, but as none of the treatments produced significant improvements in the results of semen tests or fertility they were disregarded in this analysis.

At least three semen analyses were performed by standard methods before treatment,,$^{10}$ and further analyses were requested at roughly two monthly intervals after treatment. Mean values of semen volume and sperm concentration, motility, and normal morphology before treatment were compared with those obtained in the first year after treatment by paired $t$ tests using cube root transformation of semen volume and logarithmic transformation of sperm concentration to normalise the distributions. ${ }^{11}$

Clinical information on the nature of infertility, physical examination, and details of investigations was coded for analysis by a computer as described elsewhere. ${ }^{12}$ Couples were followed up until they achieved a pregnancy, stopped trying to achieve a pregnancy, or were unable to be contacted. Life table methods were used to test for an increase in the pregnancy rate after testicular vein ligation compared with that in couples either before the operation or when no operation had been performed. ${ }^{13}$ Times were calculated in months between the date of first visit to the clinic, date of operation, estimated date of conception, or date of last contact. The "before ligation" group included $243 \mathrm{men}$ in whom there was a delay of between one and 58 months between the time of their first visit and the operation (214 had a delay of less than six months) as well as men who had not received operations or whose wives conceived before the operation. Forty men had operations within one month of their first visit. Calculation of the relative increase in pregnancy rate after ligation that could have been detected at the $5 \%$ significance level $(\alpha=0.05)$ with a given probability of type II error $(\beta=0.05)$ used the standardised normal deviate approximation.

To allow for the effects of other variables that influence pregnancy rates a Cox regression analysis was performed. ${ }^{14}$ By considering the operation as a time dependent variable we eliminated bias arising from changes in prognostic state related to timing of the operation, and the influence of the procedure on subsequent fertility was tested more precisely. ${ }^{15}$ Variables that were significantly related to pregnancy rate with $\mathrm{p}$ values of less than 0.02 were accepted in the regression equation.

\section{Results}

The life table curves of the pregnancy rates before and after testicular vein ligation were almost the same (figure). Estimates of the proportion of couples achieving a pregnancy by one and two years were $33 \cdot 2$ (SD $3 \cdot 4) \%$ and $44 \cdot 7$ $(4 \cdot 7) \%$, respectively, in the before ligation group and $29 \cdot 8(3 \cdot 3) \%$ and $47 \cdot 2$ $(5 \cdot 0) \%$, respectively, in the group of patients who had received ligation. Although few patients were followed up beyond two years the numbers in the two groups were similar. From these results there was a greater than $95 \%$ chance of finding a $25 \%$ increase in the pregnancy rate after ligation significant at the $5 \%$ level.

Comparison of the pregnancy rates before and after ligation for each size of varicocele by log rank tests showed no significant differences (table I). Variables in the Cox regression formula were in order of significance: duration of infertility, log mean sperm concentration before treatment, 


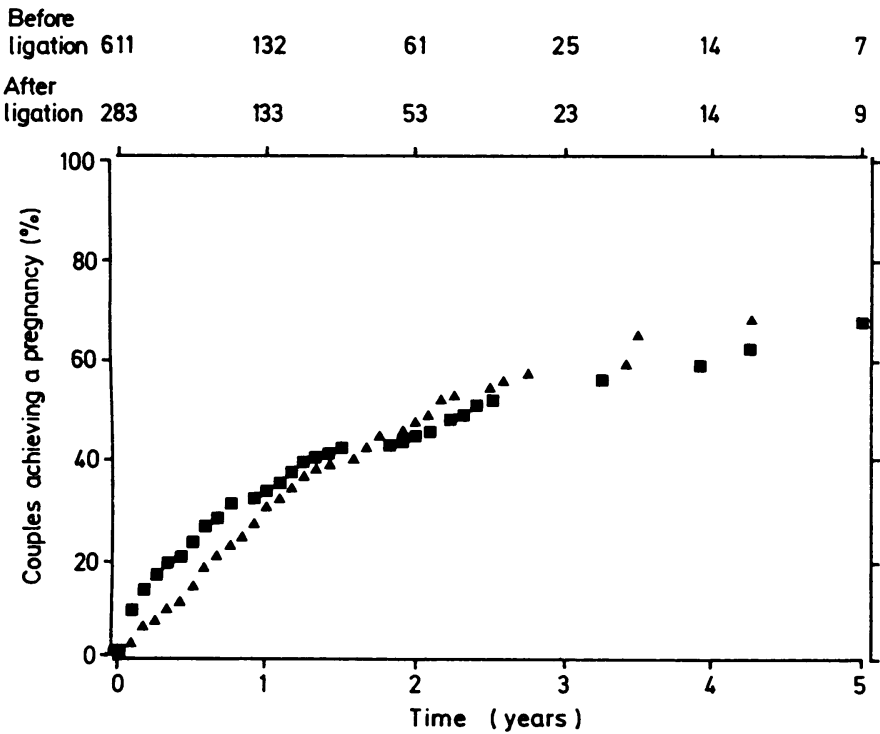

Life table curves of pregnancy rates for before ligation $(\boldsymbol{\square})$ and after ligation $(\mathbf{A})$ groups. Number of patients initially and those followed up to the end of each year is shown at top of figure. Symbols indicate those months in which the life table changed-that is, pregnancies occurred. ${ }^{12}$ Although some patients were followed up for longer than five years (those in before ligation group for maximum of 92 months, after ligation group for 108 months), the longest duration of follow up to pregnancy was 60 months. There was no significant difference between the two curves by log rank test. expressed as a cube root of the volume in $\mathrm{ml}$ (before operation 1.47 , after operation $1 \cdot 47$, standard error of the difference (SED) $0.01, p=0.924, n=$ 247); sperm concentration, expressed as a logarithm $\times 10^{6} / \mathrm{ml}$ (before operation 0.99 , after operation $1 \cdot 07$, SED $0.065, \mathrm{p}=0 \cdot 211, \mathrm{n}=247$ ); and percentage of sperm with normal morphology (before operation $58 \cdot 1$, after operation $56 \cdot 4$, SED $1 \cdot 22, \mathrm{p}=0 \cdot 18, \mathrm{n}=199$ ). Sperm motility increased significantly (before operation $33.9 \%$ after operation $39.3 \%$, SED 1.32 , $\mathrm{p}<0.001, \mathrm{n}=234)$. Sperm motility also increased to a similar extent in the first year of follow up in men with varicoceles who had not received operations (initial motility $35 \cdot 9 \%$, after follow up $40 \cdot 1 \%$, SED 1.65 , p= $0 \cdot 012, \mathrm{n}=86$ )

\section{Discussion}

After becoming aware of the uncertain value of treatment of varicoceles for infertility in 1980 , we attempted to set up a prospective controlled clinical trial in which patients were randomly allocated to operation or no operation and followed up for one year. Our trial failed because of poor recruitment and compliance with the protocol; less than $20 \%$ of eligible patients volunteered, several patients assigned to no operation had the operation within the year, and others assigned to receive ligation failed to attend for the operation. Although the trial was unsuccessful, our approach to managing men with varicoceles changed. Before 1980 patients with varicoceles were advised to have the operation to try to improve fertility and the quality of semen, but after 1980 most doctors in the clinic discussed with the couple the uncertainty of the value of treatment of varicoceles, and many patients chose not to be treated.

TABLE I-Log rank tests for pregnancy rates before and after testicular vein ligation for varicoceles of different sizes

\begin{tabular}{|c|c|c|c|c|c|c|c|}
\hline $\begin{array}{l}\text { Varicocele } \\
\text { size }\end{array}$ & Group & $\begin{array}{c}\text { No of } \\
\text { patients }\end{array}$ & $\begin{array}{c}\text { No of } \\
\text { pregnancies }\end{array}$ & $\begin{array}{l}\text { Expected } \\
\text { No of } \\
\text { pregnancies }\end{array}$ & $\begin{array}{c}\text { Relative } \\
\text { pregnancy } \\
\text { rate }\end{array}$ & $\chi^{2}$ & $\begin{array}{l}\text { Relative risk of pregnancy } \\
\text { (after ligation group } \\
\text { compared with before ligation } \\
\text { group) (95\% confidence } \\
\text { limits) }\end{array}$ \\
\hline Small & $\left\{\begin{array}{l}\text { Before ligation } \\
\text { After ligation }\end{array}\right.$ & $\begin{array}{r}236 \\
67\end{array}$ & $\begin{array}{l}72 \\
23\end{array}$ & $\begin{array}{l}68 \cdot 57 \\
26 \cdot 43\end{array}$ & $\left.\begin{array}{l}1.05 \\
0.87\end{array}\right\}$ & 0.62 & $0.83(0.40-1 \cdot 26)$ \\
\hline Medium & $\left\{\begin{array}{l}\text { Before ligation } \\
\text { After ligation }\end{array}\right.$ & $\begin{array}{l}216 \\
123\end{array}$ & $\begin{array}{l}40 \\
48\end{array}$ & $\begin{array}{l}40 \cdot 56 \\
47 \cdot 44\end{array}$ & $\left.\begin{array}{l}0.99 \\
1.01\end{array}\right\}$ & 0.01 & $1.02(0.60-1.45)$ \\
\hline Large & $\left\{\begin{array}{l}\text { Before ligation } \\
\text { After ligation }\end{array}\right.$ & $\begin{array}{r}159 \\
93\end{array}$ & $\begin{array}{l}39 \\
38\end{array}$ & $\begin{array}{l}34 \cdot 50 \\
42 \cdot 50\end{array}$ & $\left.\begin{array}{l}1 \cdot 13 \\
0 \cdot 89\end{array}\right\}$ & 1.06 & $0.79(0.39-1 \cdot 19)$ \\
\hline All (unstratified) & $\left\{\begin{array}{l}\text { Before ligation } \\
\text { After ligation }\end{array}\right.$ & $\begin{array}{l}611 \\
283\end{array}$ & $\begin{array}{l}151 \\
109\end{array}$ & $\begin{array}{l}146 \cdot 08 \\
113 \cdot 92\end{array}$ & $\left.\begin{array}{l}1.03 \\
0.96\end{array}\right\}$ & $0 \cdot 38$ & $0.93(0 \cdot 69-1 \cdot 16)$ \\
\hline
\end{tabular}

*Before ligation group included men in whom there was a delay of between one and 58 months between time of their first visit and operation as well as those who had not received operations or whose wives conceived before the operation.

TABLE II-Semen analysis categories before treatment in men with varicoceles of different sizes

\begin{tabular}{lcccc}
\hline & \multicolumn{3}{c}{ Size of left varicocele } \\
\cline { 2 - 5 } Semen category & \multicolumn{1}{c}{ Small } & Medium & Large & Total \\
\hline Sperm concentration $<1 \times 10^{6 / \mathrm{ml}}(>0)$ & 18 & 18 & 19 & 55 \\
Sperm concentration $1-5 \times 10^{6 / \mathrm{ml}}$ & 31 & 30 & 21 & 82 \\
Sperm concentration $>5-20 \times 10^{6} / \mathrm{ml}$ & 63 & 58 & 66 & 187 \\
Sperm concentration $>20 \times 10^{6} \mathrm{ml}$, motility $<60 \%$ & 113 & 101 & 60 & 274 \\
Sperm concentration $>20 \times 10^{6} / \mathrm{ml}$, motility $>60 \%$ & 19 & 19 & 15 & 53 \\
\hline Total & 244 & 226 & 181 & 651 \\
\hline
\end{tabular}

${ }^{\star}$ Normal sperm concentration $>20 \times 10^{6} / \mathrm{ml}$, sperm motility $>60 \%$.

nature of infertility (whether the man had produced pregnancies in the past), presence and size of left varicocele, and sperm autoimmunity (sperm antibodies in the serum plus failure of sperm to penetrate normal mid-cycle cervical mucus). Testicular vein ligation was also not significantly related to pregnancy rate in this analysis $\left(\chi^{2}=0 \cdot 29, \mathrm{NS}\right)$.

Table II gives the categories of semen abnormalities based on the mean results before treatment for each size of varicocele. Mean sperm concentrations were lower in men with large varicoceles (small varicoceles $44 \cdot 3 \times 10^{6} / \mathrm{ml}$, medium $35.6 \times 10^{6} / \mathrm{ml}$, and large $28 \cdot 0 \times 10^{6} / \mathrm{ml}$ ). In the first year after operation there were no significant changes in semen volume,
Thus numbers of patients followed up beyond one year in the before and after ligation groups were roughly equal. In addition, a sufficient number of pregnancies have since occurred in both groups so that the chance of not detecting a clinically relevant improvement ( $25 \%$ increase) in pregnancy rates after ligation is low (at the $5 \%$ level).

By using the Cox regression analysis, we allowed for biases due to the timing of the operation and for any difference in prognostic factors between the two groups. Thus although patients were not 
randomly allocated to receive ligation, we controlled for factors which might have invalidated the comparison of pregnancy rates -namely, unequal duration of follow up and other differences in characteristics affecting pregnancy rates in the two groups.

Interestingly, the presence of varicoceles is itself a positive prognostic factor for fertility. Patients with varicoceles produced higher pregnancy rates than those without whether or not testicular vein ligation had been performed and despite the lower sperm concentrations. Why varicoceles should be associated with better fertility in the subfertile population is uncertain. Details of this and other prognostic factors will be reported elsewhere.

Apart from an increase in sperm motility, there was no significant change in the results of semen analysis after testicular vein ligation. The increase in sperm motility was probably not due to treatment of the varicocele as it was matched by a similar increase in men with varicoceles who had not received ligation. We have also noted that sperm motility increases with time in other groups of infertile men and during the placebo phase of a controlled trial of treatment with erythromycin for low sperm motility. These spontaneous improvements may be attributed to selection bias and regression towards the mean. ${ }^{116}$

Our results strongly suggest that testicular vein ligation is not effective in increasing fertility and confirms other reports that doubt the value of treatment of varicoceles in infertile men. ${ }^{568}$ Onus is now on proponents of the treatment of varicoceles in infertile men by operation or other techniques to prove their case.

This work was supported by the National Health and Medical Research Council of Australia. We thank Ms Nola Balas, Mrs Ann Stewart, and Mrs
Elsa Newman, for help with data coding and computing, and Diane Hollingsworth, for typing.

\section{References}

1 Verstoppen GR, Steeno OP. Varicocele and the pathogenesis of the associated subfertility. A review of the various theories II: results of surgery. Andrologia 1977;9:293-305. review of the various theories II: results of surgery.
Saypol DL. Varicocele. Int $\mathcal{I}$ Androl 1981;2:61-71.

2 Saypol DL. Varicocele. Int $\mathcal{I}$ Androl 1981;2:61-71.

3 Cockett ATK, Takihara H, Cosentino JM. The varicocele. Fertil Steril 1984;41:5-11.

4 Uehling DT. Fertility in men with varicocele. Int $f$ Fertil 1968;13:58-60.

Rodriguez-Rigau LJ, Smith KD, Steinberger E. Relationship of varicocele to sperm output and fertility of male partners in infertile couples. $\mathcal{F}$ Urol 1978;120:691-4.

6 Nilsson S, Edvinsson A, Nilsson B. Improvement in semen and pregnancy rate after ligation and division of the internal spermatic vein: fact or fiction. $B r$ J Urol 1979;51:591-6.

7 De Castro MPP, Mastrorocco DAM. Reproductive history and semen analysis in prevasectomy fertile men with and without varicocele. F Androl 1984;5:17-20.

8 Vermeulen A, Vandeweghe $\mathrm{M}$. Improved fertility after varicocele correction: fact or fiction? Fertil Steril 1984:42:249-56.

9 Palomo A. Radical cure of varicocele by a new technique: preliminary report. $\mathcal{J}$ Urol 1949;61:604

10 Belsey MA, Eliasson R, Gallegos AJ, Moghissi KS, Paulsen CA, Prasad MRN. Laboratory manual for the examination of human semen and semen-cervical mucus interaction. Singapore: Press

11 Baker HWG, Burger HG, de Kretser DM, Lording DW, McGowan MP, Rennie GC. Factors affecting the variability of semen analysis results in infertile men. Int $f$ Androl 1981;4:609-22.

affecting the variability of semen analysis results in infertile men. Int $\mathcal{A}$ Androl 1981;4:609-22.
Baker HW'G, Burger HG, de Kretser DM, Hudson B. Relative incidence of etiologic disorders in male infertility. In: Santin RJ, Swerdloff RS, eds. Male sexual disfunction: diagnosis and male infertility. In: Santin RJ, Swerdloff RS, eds. Male sexual disfunction: diagnosis and management of hypogonadism, infertility and impotence. New York: Marcel Dekker (in press).

13 Peto R, Pike MC, Armitage P, et al. Design and analysis of randomized clinical trials requiring prolonged observation of each patient. II analysis and examples. Br f Cancer 1977;35:1-39.

14 Cox DR. Regression models and life tables. $\mathcal{F} R$ Stat $S_{o c}$, Series $B$ 1972;34:187-220.

15 Hopkins A. Survival analysis with covariates-Cox models. In: Dixon WJ, ed. BMDP statistical software. Berkeley: University of California Press, 1983:576-94

16 Baker HWG, Straffon WGE, McGowan MP, Burger HG, de Kretser DM, Hudson B. A controlled trial of the use of erythromycin for men with asthenospermia. Int $\mathcal{f}$ Androl 1984;7:383-388.

Accepted 8 October 1985

\title{
Electrolyte disturbances and cardiac failure with hypomagnesaemia in anorexia nervosa
}

\author{
V FONSECA, C W H HAVARD
}

\begin{abstract}
A 32 year old woman with anorexia nervosa was admitted to hospital with severe hypocalcaemia and hypokalaemia that was refractory to replacement treatment but that responded immediately to an infusion of magnesium. She also had congestive cardiac failure that responded to magnesium replacement. The mild hypomagnesaemia found in this patient was responsible for the refractory hypocalcaemia.

Minor deficiencies of magnesium may cause severe hypocalcaemia and hypokalaemia that are refractory to replacement treatment. Prompt replacement of magnesium may prevent prolonged tetany, cardiac arrhythmias, and heart failure.
\end{abstract}

\section{Introduction}

Hypomagnesaemia is associated with hypocalcaemia and hypokalaemia,' but the importance of magnesium deficiency in the aetiology of these electrolyte disturbances is not always appreciated. We report a patient with anorexia nervosa who presented with

Royal Free Hospital, London NW3

V FONSECA, MD, MRCP, senior registrar

C W H HAVARD, MD, FRCP, consultant physician and endocrinologist

Correspondence to: Dr Havard. severe hypocalcaemia and hypokalaemia that was refractory to replacement treatment but that responded immediately to an infusion of magnesium. In addition, she developed congestive cardiac failure that responded to magnesium replacement.

\section{Case report}

A 32 year old woman was admitted to hospital with weakness, paraesthesiae, and tetany. She had a long history of anorexia nervosa with chronic laxative and diuretic abuse. She had been admitted several times previously and on one occasion, a year before this latest admission, suffered a cardiorespiratory arrest, from which she was resuscitated. Apart from multivitamins, she denied taking any treatment. On examination she weighed $27 \mathrm{~kg}$. She was pale and cachectic but did not have rardiac failure. There was noticeable proximal muscle weakness as she could not raise her legs off the bed. Reflexes, however, were all present and equal, and there were no objective sensory changes. Systemic examination showed no other abnormality.

Her packed cell volume was $0 \cdot 19$; haemoglobin concentration $62 \mathrm{~g} / \mathrm{l}$; leucocyte count $12.5 \times 10^{9} / 1$; and concentrations of plasma urea $13.7 \mathrm{mmol} / \mathrm{l}$ $(82.5 \mathrm{mg} / 100 \mathrm{ml})$, plasma potassium $1.4 \mathrm{mmol}(\mathrm{mEq}) / \mathrm{l}$, plasma sodium 138 $\mathrm{mmol}(\mathrm{mEq}) / 1$, plasma bicarbonate $18 \mathrm{mmol}(\mathrm{mEq}) / 1$, plasma calcium $1 \cdot 71$ $\mathrm{mmol} / 1(6.84 \mathrm{mg} / 100 \mathrm{ml})$, plasma phosphate $0.56 \mathrm{mmol} / 1(1.7 \mathrm{mg} / 100 \mathrm{ml})$, plasma creatinine $140 \mu \mathrm{mol} / \mathrm{l}(1.6 \mathrm{mg} / 100 \mathrm{ml})$, and plasma albumin $26 \mathrm{~g} / \mathrm{l}$. Radiographs of her chest showed clear lung fields.

The patient was given a blood transfusion (four units of packed cells) and, in addition, an intravenous infusion of potassium chloride $(20 \mathrm{mmol}$ in $5 \%$ dextrose) with $1 \mathrm{~g}$ of added calcium gluconate every six hours for the next 10 days. She received 21 of fluid intravenously daily. Her haemoglobin concentration rose to $114 \mathrm{~g} / \mathrm{l}$, plasma albumin rose to $30 \mathrm{~g} / \mathrm{l}$, and blood urea fell to $5.8 \mathrm{mmol} / 1(35 \mathrm{mg} / 100 \mathrm{ml})$, but plasma calcium and potassium concentrations remained low at $1.95 \mathrm{mmol} / 1(7.8 \mathrm{mg} / 100 \mathrm{ml})$ and $3.5 \mathrm{mmol} / \mathrm{l}$, 